\title{
Psychopathology and behavior problems in children and adolescents with Williams syndrome: Distinctive relationships with cognition
}

\author{
Ana A. C. Osório, Natália F. Rossi, Óscar F. Gonçalves, Adriana Sampaio \& \\ Célia M. Giacheti
}

To cite this article: Ana A. C. Osório, Natália F. Rossi, Óscar F. Gonçalves, Adriana Sampaio \& Célia M. Giacheti (2017) Psychopathology and behavior problems in children and adolescents with Williams syndrome: Distinctive relationships with cognition, Child Neuropsychology, 23:6, 631-641, DOI: $10.1080 / 09297049.2016 .1183607$

To link to this article: https://doi.org/10.1080/09297049.2016.1183607

Published online: 25 May 2016.

Submit your article to this journal $\sqsubset$

Џ Article views: 216

Q View related articles $\longleftarrow$

View Crossmark data $\nearrow$ 


\title{
Psychopathology and behavior problems in children and adolescents with Williams syndrome: Distinctive relationships with cognition
}

\author{
Ana A. C. Osório ${ }^{a, b^{*}}$, Natália F. Rossi ${ }^{*}$, Óscar F. Gonçalves ${ }^{b, d, e}$, Adriana Sampaio $^{b}$ \\ and Célia M. Giachetic,f \\ ${ }^{a}$ Center for Biological and Health Sciences, Mackenzie Presbyterian University, São Paulo, Brazil; bCIPsi- \\ School of Psychology, University of Minho, Braga, Portugal; 'Post-Graduate Program in Speech Language \\ Pathology and Audiology, São Paulo State University (UNESP), Campus of Marília, São Paulo, Brazil; \\ dDepartment of Physical Medicine \& Rehabilitation, Spaulding Rehabilitation Hospital \& Massachusetts

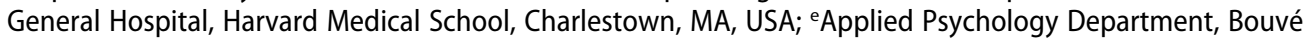 \\ College of Health Sciences, Northeastern University, Boston, MA, USA; 'Department of Speech, Language \\ Pathology and Audiology, São Paulo State University (UNESP), Marília, Brazil
}

\begin{abstract}
Several studies have documented the high prevalence of psychopathology and behavior problems in Williams syndrome (WS). However, the links between cognitive development and such symptoms need further clarification. Our study aims to expand current knowledge on levels of behavior problems and its links to cognition in a sample of Brazilian individuals with WS. A total of 25 children and adolescents with WS and their parents participated in this study. The participants' IQs were assessed with the Wechsler Scales of Intelligence (for children or adults) and parental reports of psychopathology/behavior problems were collected using the Child Behavior Checklist (CBCL). The presence of clinically significant attention problems was a main feature in our sample of children and adolescents with WS. In the children, higher IQ scores were found to be significantly associated with less externalizing problems, while in the adolescents cognitive abilities were found to be associated with less internalizing symptoms. These results provide further insight into the links between psychopathology and behavior problems and cognitive abilities in WS, and suggest the need to take age into consideration when analyzing such relationships.
\end{abstract}

\section{ARTICLE HISTORY}

Received 7 November 2014

Accepted 3 April 2016

Published online 25 May 2016

\section{KEYWORDS}

Williams syndrome;

Psychopathology; Behavior problems; Cognitive abilities

Williams syndrome (WS) is a rare neurodevelopmental disorder caused by a microdeletion on chromosome 7 (region 7q11.23; Korenberg et al., 2000) with an estimated prevalence of 1 in 7500 (Strømme, Bjømstad, \& Ramstad, 2002). This syndrome is characterized by distinctive physical (e.g., facial dysmorphia), medical (e.g., cardiovascular problems) and social-emotional (e.g., heightened empathy) features (Bellugi, Korenberg, \& Klima, 2001; Capitão et al., 2011; Mervis \& Klein-Tasman, 2000). Furthermore, individuals with WS typically display mild to moderate mental delay,

CONTACT Ana Osório ana.osorio@mackenzie.br

*Ana Osório and Natália Freitas Rossi share equal first authorship.

(c) 2016 Informa UK Limited, trading as Taylor \& Francis Group 
with relative verbal strengths contrasting with weaknesses in non-verbal domains (Atkinson et al., 2003; Bellugi, Lichtenberger, Jones, Lai, \& St. George, 2000; Farran, Jarrold, \& Gathercole, 2001; Mervis \& Klein-Tasman, 2000; Semel \& Rosner, 2003).

Beyond the aforementioned characteristics, individuals with WS have also been found to present a higher than expected prevalence of hyperactive and impulsive symptoms. Indeed, attention-deficit/hyperactivity disorder (ADHD) is one of the most frequent comorbid diagnoses (Dodd \& Porter, 2009; Kennedy, Kaye, \& Sadler, 2006; Leyfer, Woodruff-Borden, Klein-Tasman, Fricke, \& Mervis, 2006; Martens et al., 2013; Rhodes, Riby, Matthews, \& Coghill, 2011). Furthermore, a study by Dykens (2003) conducted on a large sample of individuals with WS found that they display significantly more fears and a wider range of fears than a comparison group of individuals with intellectual disability of mixed etiologies. The author also reported a particularly high incidence of anxiety disorders, namely specific phobia, and symptoms of generalized anxiety disorder in the WS group. Similarly, a study conducted by Leyfer et al. (2006) in a large sample of children with WS reported that specific phobia and generalized anxiety disorder were two of the three most prevalent comorbid diagnoses, affecting around $54 \%$ and $12 \%$ of the children, respectively.

Additional reports on behavioral and emotional disturbances also contributed to a better definition of the WS profile (for a review, see Martens, Wilson, \& Reutens, 2008). Einfeld, Tonge, and Florio (1997) administered the Developmental Behavior Checklist (DBC; Einfeld \& Tonge, 1995) - a tool specifically developed for populations with intellectual disability - to parents of 70 children and adolescents with WS. The authors found that the clinical sample scored significantly higher on Total Behavior Problems, as well on the Communication Disturbance and the Anxiety subscales, when compared to an epidemiological control sample. Using the Child Behavior Checklist (CBCL) 1.55 years, Papaeliou et al. (2012) compared the level of behavior problems between samples of Greek preschool-age children with WS, Down syndrome and typical development, matched in mental age. The authors found higher rates of emotional problems, anxiety/depression and internalizing problems in the WS sample. In addition, $40 \%$ of their WS sample were on the borderline/clinical range on Attention Problems. Using the school-age version of the CBCL, Greer, Brown, Pai, Choudry, and Klein (1997) reported clinically significant levels on the Attention Problems scale in their sample of children with WS, with $73 \%$ scoring in the clinical range and $87 \%$ scoring in the borderline and clinical ranges. Furthermore, mean borderline levels were also found in the Social Problems and Thought Problems scales.

In terms of the link between cognitive development and psychopathology or behavior problems, results so far are scarce and relatively inconsistent. While two teams found no associations between general cognitive ability and personality features (Dykens \& Rosner, 1999) or psychopathology (Leyfer et al., 2006) in WS, others have found some evidence for associations in distinct age ranges. For instance, $\mathrm{Ng}$, Järvinen, and Bellugi (2014) recently reported a positive association between cognitive ability and anxiety symptoms in a sample of mature individuals with WS (mean age of 33 years). On the other hand, Porter, Dodd, and Cairns (2009) found that Woodcock-Johnson IQ scores normalized to individual performance-Processing Speed, Comprehension/ Knowledge and Auditory Processing-were correlated with several CBCL scales. More specifically, relative Processing Speed was negatively correlated with Total Problems 
and Internalizing as well as with three scales related to the Diagnostic and Statistical Manual of Mental Disorders (DSM)-Affective, Somatic and Conduct DSM. In contrast, relative abilities in Comprehension/Knowledge were positively correlated with Internalizing and Affective DSM, and relative Auditory Processing was positively correlated with Conduct DSM. Nevertheless, the authors noted that they found no associations between untransformed IQ scores and any of the CBCL scales, and therefore their study provided evidence for relationships between psychopathology and specific cognitive strengths and weaknesses in individuals with WS. Despite the relevant contributions of this study, it must be noted that their sample was composed of patients aged 6 to 48. Due to the distinct developmental challenges faced by children, adolescents and adults - not only at a cognitive level but also in terms of psychopathology and behavior problems-it is particularly relevant to address the links between such variables in narrower age ranges, focusing specifically on children and adolescents. In this line, a recent study by Klein-Tasman, Lira, Li-Barber, Gallo, and Brei (2015) devoted to analyzing the concordance between parent and teacher reports of behavior problems (using Achenbach System of Empirically Based Assessment-ASEBA-forms) found that intellectual functioning of their sample of 52 children (6 to 17 years) was negatively correlated with teachers' Thought Problems scale reports. However, to the best of our knowledge, to date no studies have sought to explore the links between intellectual ability and CBCL scores in samples other than North American or European.

The aim of our study is to offer further clarification on previous work by exploring the relationships between measures of psychopathology/behavior problems and cognitive ability in a sample of Brazilian children and adolescents with WS.

\section{Method}

\section{Participants}

The sample was composed of 25 children and adolescents with WS ( $n=14$ males, 56\%) recruited at the Brazilian Williams Syndrome Association. Descriptive statistics for age and sex are presented in Table 1. A total of 8 participants were aged from 7 to 12 years $(M=9.63$ years, $S D=1.51,7$ males, 1 female), and the remaining 17 were aged $13-$ 18 years $(M=15.06$ years, $S D=1.34,7$ males, 10 females $)$. Diagnoses were previously established by the presence of the physical and behavioral phenotypes consistent with the syndrome, as well as the presence of genetic deletions on 7q11.23 detected by fluorescent in situ hybridization (FISH).

Table 1. Descriptive Statistics for Age, Cognitive Ability and Sex.

\begin{tabular}{lcc}
\hline & $M(S D)$ & Range \\
\hline Age & $13.32(2.93)$ & $7-18$ \\
Cognitive ability & & \\
FSIQ & $55.76(8.54)$ & $49-78$ \\
VIQ & $57.36(11.22)$ & $45-76$ \\
PIQ & $57.66(10.34)$ & $45-78$ \\
Sex & $N$ & $\%$ \\
Male & 14 & 56 \\
Female & 11 & 44 \\
\hline
\end{tabular}


After a complete description of the study, participants' parents provided written informed consent for participation.

\section{Materials}

\section{General cognitive functioning}

\section{Wechsler intelligence scales}

The Brazilian versions of the Wechsler Intelligence Scale for Children - Third Edition (WISC-III; Figueiredo, 2001) and Wechsler Adult Intelligence Scale - Third Edition (WAIS-III; Nascimento, 2004) were administered to assess general cognitive functioning in participants 16 and under (WISC-III) and participants over 16 (WAIS-III). These scales are widely used in typical development as well as in mild and moderate mental retardation, including in WS. The WISC-III and WAIS-III yield scores for Full Scale IQ (FSIQ), Verbal IQ (VIQ) and Performance IQ (PIQ).

\section{Behavior problems}

\section{Child behavior checklist (CBCL)}

The CBCL (6-18; Parent Report Form; Achenbach \& Rescorla, 2001; Brazilian adaptation by Bordin et al., 2009) is one of the most widely used measures of behavior problems. It relies on parental reports of behavior problems of children and adolescents aged 6-18 years, and has been used reliably in WS samples (Greer et al., 1997; Porter et al., 2009). Behaviors are rated on a three-point Likert-type scale ( $0=$ not true; 1 = somewhat or sometimes true; 2 = very true or often true), yielding the following syndrome scales: Anxious/Depressed, Withdrawn/Depressed, Somatic Complaints, Social Problems, Thought Problems, Attention Problems, Rule-breaking Behavior and Aggressive Behavior. These syndrome scales are further summed into the two factors Internalizing and Externalizing, as well as a Total Problem score. In the present study we used the $t$-scores of the CBCL scales, which can be classified as follows: $<65=$ normal range, $65-69=$ borderline range, $\geq 70=$ clinical range.

\section{Procedure}

After explaining the goals of the research to the participants and their parents, and obtaining their informed consent, social-demographic information was collected. The WISC-III/ WAIS-III was administered individually at the Brazilian Williams Syndrome Association offices, in two sessions lasting approximately 1 hour each. While children and adolescents were undergoing the cognitive assessment, parents were asked to fill out the CBCL.

The Ethics Committee of the Botucatu Medicine Faculty (UNESP Campus) approved the present study (OF256/2006-CEP).

\section{Statistical methods}

Statistical calculations were performed using PASW Statistics 18 (IBM; SPSS Inc., 2009). Non-parametric Mann-Whitney tests were conducted to test for differences in 
age, IQ and CBCL scores between males and females. Spearman correlations were conducted to explore the pattern of relationships between CBCL scores and general cognitive functioning in children and adolescents. Effect sizes were interpreted according to the criteria by Cohen (1992).

\section{Results}

Descriptive statistics for cognitive ability are shown in Table 1. Mean FSIQ was in the mild intellectual disability range.

Table 2 summarizes the descriptive statistics for each CBCL $t$-score. Regarding the total sample, the mean score for Attention Problems was in the clinical range, while the mean scores for Total Problems, Anxious/Depressed, Social Problems and Thought Problems were in the borderline range. In contrast, mean scores for Internalizing, Externalizing, Withdrawn/Depressed, Somatic Complaints, Rule-breaking Behavior and Aggressive Behavior were in the normal range.

Figure 1 shows the distribution of patients attaining non-clinical vs. clinical/borderline scores. More than half of the sample was classified in the clinical/borderline category in the following scales: Total Problems (64\%), Internalizing (60\%), Anxious/ Depressed (72\%), Social Problems (64\%), Thought Problems (68\%) and Attention Problems (76\%). For the remaining scales, distributions of clinical/borderline scores in the sample were as follows: Externalizing (20\%), Withdrawn/Depressed (40\%), Somatic Complaints (28\%), Rule-breaking Behavior (24\%) and Aggressive Behavior (24\%).

\section{Differences between males and females}

Non-parametric Mann-Whitney tests revealed no differences in age $(U=104.50$, $p=.390$ ) or cognitive ability (FSIQ, $U=108.00, p=.45$; VIQ, $U=111.00, p=.53$; PIQ, $U=100.00, p=.30$ ) between the sexes. Males and females were also indistinguishable in all of the CBCL scores (Total, $U=66.50, p=.56$; Externalizing, $U=75.00$, $p=.91$; Internalizing, $U=48.50, p=.12$; Withdrawn/Depressed, $U=50.50, p=.14$; Somatic Complaints, $U=66.00, p=.55$; Anxious/Depressed, $U=55.50, p=.24$; Social Problems, $U=71.50, p=.76$; Thought Problems, $U=56.00, p=.25$; Attention

Table 2. Descriptive Statistics for CBCL $t$-scores.

\begin{tabular}{lcr}
\hline & $M(S D)$ & Range \\
\hline Total Score & $66.72(5.25)$ & $55-77$ \\
Internalizing & $64.60(5.92)$ & $50-72$ \\
Externalizing & $59.04(7.00)$ & $46-77$ \\
Anxious/Depressed & $66.12(6.84)$ & $52-82$ \\
Withdrawn/Depressed & $60.20(8.40)$ & $50-75$ \\
Somatic Complaints & $58.96(7.71)$ & $50-72$ \\
Social Problems & $67.72(7.08)$ & $58-87$ \\
Thought Problems & $67.60(7.10)$ & $55-78$ \\
Attention Problems & $72.84(9.94)$ & $59-93$ \\
Rule-breaking Behavior & $57.92(5.95)$ & $51-71$ \\
Aggressive Behavior & $59.80(8.18)$ & $50-87$ \\
\hline
\end{tabular}




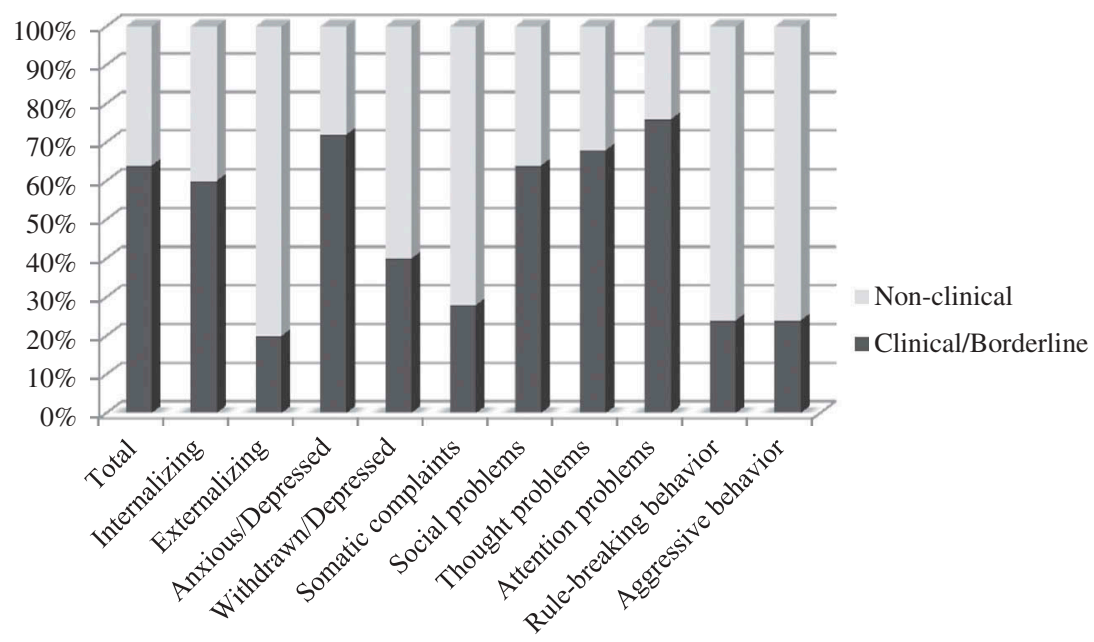

Figure 1. CBCL Clinical/Borderline vs. Non-Clinical Profile Proportions.

Problems, $U=73.00, p=.83$; Rule-breaking Behavior, $U=58.00, p=.29$; Aggressive Behavior, $U=71.50, p=.76)$.

\section{Relationships between cognitive ability and the $C B C L$}

The pattern of relationships between IQ and CBCL scores is presented in Table 3, separately for each age group. In the group of children, a significant proportion of the variance was shared between Rule-breaking Behavior and FSIQ (56\%), and slightly less with VIQ (42\%) and PIQ (40\%). Effect sizes for these associations were large. Even though Externalizing and IQ scores were not significantly related, it is worth noting that the effect sizes for the correlations between Externalizing and FSIQ and PIQ were moderate (shared variance of $16 \%$ and $13 \%$, respectively).

In the group of adolescents, $20 \%$ of the variance was shared between PIQ and Total Problems. In turn, 45\%, 27\% and $24 \%$ of the variance were shared between Internalizing and PIQ, VIQ and FSIQ, respectively (all effect sizes large). Regarding

Table 3. Relationships between Cognitive Ability and Behavior Problems.

\begin{tabular}{|c|c|c|c|c|c|c|}
\hline & \multicolumn{3}{|c|}{$\begin{array}{l}\text { Children } \\
(n=8)\end{array}$} & \multicolumn{3}{|c|}{$\begin{array}{l}\text { Adolescents } \\
(n=17)\end{array}$} \\
\hline & FSIQ & VIQ & PIQ & FSIQ & VIQ & PIQ \\
\hline Total & -.20 & -.05 & -.32 & -.18 & -.39 & $-.45^{+}$ \\
\hline Internalizing & .19 & .40 & .03 & $-.49^{*}$ & $-.52^{*}$ & $-.69^{* *}$ \\
\hline Externalizing & -.40 & -.26 & -.36 & .19 & .02 & .25 \\
\hline Anxious/Depressed & .23 & .33 & .18 & $-.51^{*}$ & $-.51^{*}$ & $-.63^{* *}$ \\
\hline Withdrawn/Depressed & .26 & .35 & .10 & $-.56^{+}$ & $-.53^{*}$ & -.40 \\
\hline Somatic Complaints & -.19 & .04 & -.40 & .10 & -.07 & -.32 \\
\hline Social Problems & -.35 & -.22 & -.34 & -.32 & $-.50^{*}$ & -.33 \\
\hline Thought Problems & .15 & .22 & .05 & -.03 & -.41 & -.30 \\
\hline Attention Problems & .08 & -.16 & .10 & -.02 & -.11 & .01 \\
\hline Rule-breaking Behavior & $-.75^{*}$ & $-.65^{+}$ & $-.63^{+}$ & .26 & .22 & -.18 \\
\hline Aggressive Behavior & -.21 & -.07 & -.26 & .05 & -.20 & -.23 \\
\hline
\end{tabular}

Note. ${ }^{+} p<.10 ;{ }^{*} p<.05 ;{ }^{* *} p<.01$. 
Withdrawn/Depressed, shared variance amounted to 31\% with FSIQ and 28\% with VIQ (both effect sizes large). For Anxious/Depressed, 40\% of the variance was shared with PIQ and 26\% with FSIQ and VIQ (all effect sizes large). Finally, the shared variance between Social Problems and VIQ was 25\% (large effect size). Therefore, in the older age group, higher percentages of shared variance were found between IQ scores and several CBCL scores related to internalizing symptoms.

\section{Discussion}

The aim of our study was to test the relationships between psychopathology/behavior problems (assessed by the CBCL) and cognitive ability (assessed by the Wechsler scales). This was the first study to explore such relationships in a Brazilian sample of children and adolescents with WS.

Regarding the CBCL, in this sample of participants, the mean score for Attention Problems was in the clinical range, and more than two thirds of the sample was classified in the clinical/borderline categories (76\%). Similar results were previously reported by Greer et al. (1997), who found that $73 \%$ of their sample presented clinically significant scores for Attention Problems. This result is also in line with evidence indicating that impairments in attention are a distinctive feature of the WS profile (Dodd \& Porter, 2009; Gagliardi, Martelli, Tavano, \& Borgatti, 2011; Kennedy et al., 2006; Leyfer et al., 2006; Semel \& Rosner, 2003), including one study conducted with a small sample of Brazilian children with WS (Teixeira, Monteiro, Velloso, Kim, \& Carreiro, 2010). Similar to reports by Greer et al. (1997), we found that mean scores for Social Problems and Thought Problems were in the borderline range. Furthermore, our sample of participants attained mean borderline scores on two additional CBCL scales-Total Problems and Anxious/Depressed. In fact, regarding the latter, there is consistent evidence that children and adults with WS display high levels of non-social anxiety, including specific phobia and generalized anxiety symptoms (Dykens, 2003; Gagliardi et al., 2011; Leyfer et al., 2006; Woodruff-Borden, Kistler, Henderson, Crawford, \& Mervis, 2010). The present study, along with the work of Teixeira et al. (2010), provides the first evidence of CBCL problem scores in samples of South American children and adolescents with WS.

Despite the fact that the proportion of participants in the borderline/clinical range is similar to most previous reports, it is significantly higher than the recent reports by Klein-Tasman et al. (2015) for American children with WS. Cross-cultural comparisons for the CBCL 6-18 suggest that parents in Brazil tend to report higher rates of mean problem scores than parents in the United States (US), highlighting the importance of multicultural norms (Rocha et al., 2013). Nevertheless, it is noteworthy that the work by Rocha et al. (2013), conducted with parents of 1228 non-referred and 247 referred Brazilian children aged 6-11 years, found that mean item ratings and scale internal consistencies for the CBCL 6-18 were very similar to those found in the US. Indeed, confirmatory factor analyses also indicated that their data on Brazilian children showed an excellent fit to the US model. Overall, their findings replicated international comparisons of CBCL scores for 31 societies, thus supporting the multicultural robustness of the CBCL in Brazil (Rocha et al., 2013). 
In what concerns sex differences, males and females were indistinguishable in cognitive ability and in each of the CBCL scores. Overall, our results for the CBCL replicate those reported by Greer et al. (1997) and more recently by Klein-Tasman et al. (2015) - two studies that covered a similar age range-and thus offer additional support to the notion that at younger ages, males and females with WS present similar levels of psychopathology and behavior problems.

We also analyzed the pattern of associations between intellectual ability and CBCL scores for children and adolescents separately. As the number of children and adolescents was uneven, results should be viewed as preliminary. Cognitive abilities were significantly associated with psychopathology and behavior problems, albeit differently in children and adolescents. While the children's IQ scores shared a significant amount of variance with Rule-breaking and, to a lesser extent, Externalizing, an important proportion of variance was shared between the adolescents' IQ scores and Anxious/ Depressed, and more generally with Internalizing. These two distinct patterns of results suggest that intellectual abilities are associated with fewer symptoms in the domain of Externalizing (particularly Rule-breaking Behavior) in children, whereas such abilities are linked to decreased Internalizing symptoms (including Anxious/Depressed) in adolescents. Thus, and as seen in typical development, self-regulatory processes are very important developmental milestones for children with WS and are likely to develop hand in hand with cognition. In contrast, the internalizing domain takes on particular relevance in the teenage years and thus intellectual abilities may be more relevant for symptoms emerging in this domain.

Interestingly, our results are in contrast to recent reports by $\mathrm{Ng}$ et al. (2014) of a significant positive association between subjective reports of anxiety and verbal ability in a mature sample of individuals with WS. According to the authors, higher verbal ability may increase the risk of experiencing and expressing psychological anxiety but only in WS, as they reported the reverse pattern for their typically developed control sample. However, the apparent inconsistencies between $\mathrm{Ng}$ et al. and our own results may in fact be due to several important methodological differences. Firstly, the age ranges of both samples are markedly different-while our sample was composed exclusively of children and adolescents (mean age of 13 years), $\mathrm{Ng}$ et al. assessed adults (mean age of 33 years). Furthermore, and in line with such age differences, we conducted a more broad assessment of behavior problems (including anxiety) using the CBCL, while Ng et al. targeted distinct anxiety dimensions using the Beck Anxiety Inventory. Finally, it is also noteworthy that the mean VIQ of $\mathrm{Ng}$ et al.'s sample is significantly higher than our sample of younger individuals with WS. ${ }^{1}$ Our findings are in accordance with a protective effect of intelligence on internalizing symptoms in adolescents and on externalizing symptoms in children with WS. Therefore, children and adolescents with better cognitive abilities may be more capable of better regulating both behavior and emotion.

Despite the importance of analyzing data separately for different age ranges, interpretative caution should be used insofar as there was an unequal distribution of children and adolescents in our sample. Thus, future studies should attempt to replicate the present findings in a sample with a more balanced ratio between children and adolescents. Another important shortcoming is the absence of a control group, which would certainly allow for important comparisons and contrasts in terms of CBCL 
problem scores and their links to cognitive ability. Future studies might consider including typically developing as well as clinical (e.g., other developmental disorders) comparison groups.

In conclusion, our study showed that the presence of clinically significant scores with Attention Problems was a main feature in our sample of children and adolescents with WS. Furthermore, males and females with WS were indistinguishable in terms of psychopathology and behavior problems, as well as cognitive ability. Finally, while better cognitive abilities were significantly associated with less externalizing problems in children (such as rule-breaking behavior), these abilities were associated with less internalizing symptoms in adolescents. Our results highlight the need to take age into consideration when analyzing the link between psychopathology/behavior problems and cognitive abilities in WS.

\section{Note}

1. $M=71.35, S D=9.05$ vs. $M=57.36, S D=11.22, t(85)=6.08, p<.001$.

\section{Disclosure Statement}

No potential conflict of interest was reported by the authors.

\section{Funding}

This work was supported by CAPES [grant numbers BEX 1551/08-6 and BEX 9573/11-9]; CNPq [grant numbers 308540/2012-3 and 487188/2013-6]; and FEDER through the Competitive Factors Operational Programme (COMPETE) and national funds from the Portuguese Foundation for Science and Technology [grant number PTDC/PSI-PCL/115316/2009].

\section{References}

Achenbach, T. M., \& Rescorla, L. A. (2001). Manual for the ASEBA school-age forms \& profiles. Burlington: Research Centre for Children, Youth and Families, University of Vermont.

Atkinson, J., Braddick, O., Anker, S., Curran, W., Andrew, R., Wattam-Bell, J., \& Braddick, F. (2003). Neurobiological models of visuospatial cognition in children with Williams syndrome: Measures of dorsal-stream and frontal function. Developmental Neuropsychology, 23(1-2), 139-172. doi:10.1080/87565641.2003.9651890

Bellugi, U., Korenberg, J. R., \& Klima, E. S. (2001). Williams syndrome: An exploration of neurocognitive and genetic features. Clinical Neuroscience Research, 1(3), 217-229. doi:10.1016/S1566-2772(01)00008-1

Bellugi, U., Lichtenberger, L., Jones, W., Lai, Z., \& St. George, M. (2000). I. The neurocognitive profile of Williams syndrome: A complex pattern of strengths and weaknesses. Journal of Cognitive Neuroscience, 12, 7-29. doi:10.1162/089892900561959

Bordin, I. A., Duarte, C. S., Peres, C. A., Nascimento, R., Curto, B. M., \& Paula, C. S. (2009). Severe physical punishment: Risk of mental health problems for poor urban children in Brazil. Bulletin of the World Health Organization, 87(5), 336-344. doi:10.2471/BLT.07.043125

Capitão, L., Sampaio, A., Férnandez, M., Sousa, N., Pinheiro, A., \& Gonçalves, Ó. F. (2011). Williams syndrome hypersociability: A neuropsychological study of the amygdala and prefrontal cortex hypotheses. Research in Developmental Disabilities, 32, 1169-1179. doi:10.1016/j. ridd.2011.01.006 
Cohen, J. (1992). A power primer. Psychological Bulletin, 112(1), 155-159. doi:10.1037/00332909.112.1.155

Dodd, H. F., \& Porter, M. A. (2009). Psychopathology in Williams syndrome: The effect of individual differences across the life span. Journal of Mental Health Research in Intellectual Disabilities, 2(2), 89-109. doi:10.1080/19315860902725867

Dykens, E. (2003). Anxiety, fears, and phobias in persons with Williams syndrome. Developmental Neuropsychology, 23(1-2), 291-316. doi:10.1080/87565641.2003.9651896

Dykens, E., \& Rosner, B. (1999). Refining behavioral phenotypes: Personality-motivation in Williams and Prader-Willi syndromes. American Journal on Mental Retardation, 104(2), 158-169. doi:10.1352/0895-8017(1999)104<0158:RBPPIW >2.0.CO;2

Einfeld, S. L., \& Tonge, B. J. (1995). The developmental behavior checklist: The development and validation of an instrument to assess behavioral and emotional disturbance in children and adolescents with mental retardation. Journal of Autism and Developmental Disorders, 25(2), 81-104. doi:10.1007/BF02178498

Einfeld, S. L., Tonge, B. J., \& Florio, T. (1997). Behavioral and emotional disturbance in individuals with Williams syndrome. American Journal on Mental Retardation, 102(1), 4553. doi:10.1352/0895-8017(1997)102<0045:BAEDII>2.0.CO;2

Farran, E. K., Jarrold, C., \& Gathercole, S. E. (2001). Block design performance in the Williams syndrome phenotype: A problem with mental imagery? Journal of Child Psychology and Psychiatry, 42(6), 719-728. doi:10.1111/jcpp.2001.42.issue-6

Figueiredo, V. L. M. (2001). Escala de inteligência Wechsler para crianças. São Paulo: Casa do Psicólogo.

Gagliardi, C., Martelli, S., Tavano, A., \& Borgatti, R. (2011). Behavioural features of Italian infants and young adults with Williams-Beuren syndrome. Journal of Intellectual Disability Research, 55(2), 121-131. doi:10.1111/j.1365-2788.2010.01376.x

Greer, M. K., Brown, F. R., III, Pai, G. S., Choudry, S. H., \& Klein, A. J. (1997). Cognitive, adaptive, and behavioral characteristics of Williams syndrome. American Journal of Medical Genetics, 74(5), 521-525. doi:10.1002/(ISSN)1096-8628

Kennedy, J. C. M. D., Kaye, D. L. M. D., \& Sadler, L. S. M. D. (2006). Psychiatric diagnoses in patients with Williams syndrome and their families. Jefferson Journal of Psychiatry, 20(1), 4.

Klein-Tasman, B. P., Lira, E. N., Li-Barber, K. T., Gallo, F. J., \& Brei, N. G. (2015). Parent and teacher perspectives about problem behavior in children with Williams syndrome. American Journal on Intellectual and Developmental Disabilities, 120(1), 72-86. doi:10.1352/1944-7558120.1 .72

Korenberg, J. R., Chen, X.-N., Hirota, H., Lai, Z., Bellugi, U., Burian, D. .. Matsuoka, R. (2000). VI. Genome structure and cognitive map of Williams syndrome. Journal of Cognitive Neuroscience, 12(Supplement 1), 89-107. doi:10.1162/089892900562002

Leyfer, O. T., Woodruff-Borden, J., Klein-Tasman, B. P., Fricke, J. S., \& Mervis, C. B. (2006). Prevalence of psychiatric disorders in 4 to 16 -year-olds with Williams syndrome. American Journal of Medical Genetics Part B: Neuropsychiatric Genetics,141B(6), 615-622. doi:10.1002/ (ISSN)1552-485X

Martens, M. A., Seyfer, D. L., Andridge, R. R., Foster, J. E., McClure, K. E., \& Coury, D. L. (2013). Caregiver survey of pharmacotherapy to treat attention deficit/hyperactivity disorder in individuals with Williams syndrome. Research in Developmental Disabilities, 34(5), 17001709. doi:10.1016/j.ridd.2013.02.015

Martens, M. A., Wilson, S. J., \& Reutens, D. C. (2008). Research review: Williams syndrome: A critical review of the cognitive, behavioral, and neuroanatomical phenotype. Journal of Child Psychology and Psychiatry, 49(6), 576-608. doi:10.1111/j.1469-7610.2008.01887.x

Mervis, C. B., \& Klein-Tasman, B. P. (2000). Williams syndrome: Cognition, personality, and adaptive behavior. Mental Retardation and Developmental Disabilities Research Reviews, 6(2), 148-158. doi:10.1002/(ISSN)1098-2779

Nascimento, E. (2004). Adaptação, validação e normatização do WAIS-III para uma amostra brasileira. São Paulo: Casa do Psicólogo. 
Ng, R., Järvinen, A., \& Bellugi, U. (2014). Characterizing associations and dissociations between anxiety, social, and cognitive phenotypes of Williams syndrome. Research in Developmental Disabilities, 35(10), 2403-2415. doi:10.1016/j.ridd.2014.06.010

Papaeliou, C., Polemikos, N., Fryssira, E., Kodakos, A., Kaila, M., Yiota, X., ... Vrettopoulou, M. (2012). Behavioural profile and maternal stress in Greek young children with Williams syndrome. Child: Care, Health and Development, 38(6), 844-853.

Porter, M. A., Dodd, H., \& Cairns, D. (2009). Psychopathological and behavior impairments in Williams-Beuren syndrome: The influence of gender, chronological age, and cognition. Child Neuropsychology, 15(4), 359-374. doi:10.1080/09297040802577881

Rhodes, S. M., Riby, D. M., Matthews, K., \& Coghill, D. R. (2011). Attention-deficit/hyperactivity disorder and Williams syndrome: Shared behavioral and neuropsychological profiles. Journal of Clinical and Experimental Neuropsychology, 33(1), 147-156. doi:10.1080/ 13803395.2010 .495057

Rocha, M. M., Rescorla, L. A., Emerich, D. R., Silvares, E. F. M., Borsa, J. C., Araújo, L. G. S., ... Assis, S. G. (2013). Behavioural/emotional problems in Brazilian children: Findings from parents' reports on the child behavior checklist. Epidemiology and Psychiatric Sciences, 22 (04), 329-338. doi:10.1017/S2045796012000637

Semel, E., \& Rosner, S. (2003). Understanding Williams syndrome: Behavioral patterns and interventions. Mahwah, NJ: Lawrence Erlbaum Associates.

Strømme, P., Bjømstad, P. G., \& Ramstad, K. (2002). Prevalence estimation of Williams syndrome. Journal of Child Neurology, 17(4), 269-271. doi:10.1177/088307380201700406

SPSS Inc. Released 2009. PASW Statistics for Windows [version 18.0]. Chicago, IL: Author.

Teixeira, M. C. T. V., Monteiro, C. R. C., Velloso, R. D. L., Kim, C., \& Carreiro, L. R. R. (2010). Behavioral and cognitive phenotype of children and adolescents with Williams-Beuren syndrome. Pró-Fono Revista de Atualização Científica, 22(3), 215-220. doi:10.1590/S010456872010000300010

Woodruff-Borden, J., Kistler, D. J., Henderson, D. R., Crawford, N. A., \& Mervis, C. B. (2010). Longitudinal course of anxiety in children and adolescents with Williams syndrome. Paper presented at the American Journal of Medical Genetics Part C: Seminars in Medical Genetics, 154C, 277-290. doi:10.1002/ajmg.c.v154c:2 